\title{
Comparison of Conventionally Measured Serum Bicarbonate Values with Bicarbonate Values Obtained in Arterial and Venous Blood Gas Analysis
}

\author{
W Nargis ${ }^{1}$, BU Ahamed ${ }^{2}$, Z Hossain ${ }^{3}$, S Zabeen ${ }^{4}$, N Houqe ${ }^{5}$ \\ ${ }^{1}$ Dept of Biochemistry, Uttara Adhunik Medical College, Dhaka \\ 2Dept of Surgery, Uttara Adhunik Medical College, Dhaka \\ ${ }^{3}$ Dept of Anesthesiology, Uttara Adhunik Medical College, Dhaka \\ ${ }^{4}$ Dept of Biochemistry, Anwer Khan Modern Medical College, Dhaka \\ 5 Dept of Biochemistry, Faridpur Medical College, Faridpur
}

\begin{abstract}
Bicarbonate $\left(\mathrm{HCO}_{3}{ }^{-}\right)$measurement in serum or plasma from a sample of venous blood is routinely practiced in hospital patient management. $\mathrm{HCO}_{3}{ }^{-}$status can also be assumed from Blood gas analysis requiring arterial blood as sample which is cumbersome for both patients and doctors. This study was undertaken to evaluate the extent of agreement among biocarbonate values obtained during venous, arterial blood gas analysis and conventionally measured serum bicarbonate levels in a group of intensive care unit (ICU) patients to determine whether conventionally measured serum $\mathrm{HCO}_{3}{ }^{-}$(from peripheral venous blood) and calculated $\mathrm{HCO}_{3}{ }^{-}$values (from arterial blood gas [ABG] analyzers) can be used interchangeably. A total of 51 adult patients with diverse medical conditions, presenting at a tertiary health centre ICU were enrolled in this study when deemed by the treating physician to have an ABG analysis. Arterial and venous samples were taken as close in time as possible for blood gas analysis and routine blood tests. Bland-Altman analyses were used to compare the three methods. The $\mathrm{HCO}_{3}{ }^{-}$levels from $\mathrm{ABG}$, Venous Blood gas (VBG) and tconventionally measured serum $\mathrm{HCO}_{3}{ }^{-}$showed acceptably narrow $95 \%$ limits of agreement using the Bland-Altman method. VBG reveals higher level of agreement with the ABG bicarbonate values compared to measured serum $\mathrm{HCO}_{3}{ }^{-}$. Thus, venous blood can be an alternate for arterial blood where ABG analyzer is available. conventionaly serum $\mathrm{HCO}_{3}{ }^{-}$ measurements can also be useful and used as substitute for an expensive ABG analyzer in resource constrained health care sectors when required.
\end{abstract}

Keywords: Arterial blood gas analysis, Venous blood gas analysis, Measured serum bicarbonate, Intensive Care Unit.

\section{Introduction}

The measurement of bicarbonate level in blood is extremely common and often provides vitally important data used in the care of critically ill patients. The bicarbonate level in blood can be directly measured or derived from calculations using the Henderson-Hasselbalch equation; mostly adopted by the blood gas analyzers ${ }^{1}$. Arterial blood gas (ABG) analysis is commonly performed for clinical evaluation, but the procedure has certain limitations in the form of reduced patient acceptability because of painful procedure and the potential to cause complications such as arterial injury, thrombosis Bangladesh J Med Biochem 2012; 5(1): 12-15 with distal ischaemia, haemorrhage, aneurysm formation, median nerve damage and reflex sympathetic dystrophy ${ }^{2,3}$. Venous blood gas (VBG) analysis is a relatively safer procedure as fewer punctures are required thus reducing the risk of needle stick injury to the health care workers.

Although various studies suggest that a venous sample is relatively accurate for acid-base assessment $^{3-8}$, VBG analysis has not gained much acceptance as a substitute for $A B G$ analysis. On the contrary, bicarbonate ions make 
up $\sim 95 \%$ of the total carbon dioxide of the plasma and hence both of them have been used interchangeably. Most blood gas analyzers use the Henderson-Hasselbach equation to calculate bicarbonate values based on the assumption that the dissociation constant $(\mathrm{pK})$ and solubility coefficient $(\alpha)$ are invariant. However, $\mathrm{pK}$ is affected by changes in $\mathrm{pH}$, ionic strength and temperature while the values of $\alpha$ varies with the composition of the solution such as the presence of increased salts proteins or lipids ${ }^{1}$. Therefore, the calculated bicarbonate values irrespective of the type of sample, may have significant error under certain circum stances, making its reliability questionable. Previous studies using different statistical methods to assess the agreement between measured and calculated bicarbonate have shown conflicting results with some studies showing good agreement ${ }^{9-12}$, while some studies showed otherwise ${ }^{13-15}$.

So far this study is concerned, the feasibility of such expensive procedure in a middle income country like ours is intended to be reconsidered. However, nearly all medical centers in Bangladesh have the conventional laboratory methods to determine the concentrations of this key analyte in routine venous blood. But arterial blood gas analyzers are still limited to a small number of referral hospitals. This study was aimed to investigate the extent of agreement among bicarbonate values obtained in venous and arterial blood gas analysis and conventionally measured serum bicarbonate levels in a group of intensive care unit (ICU) patients to determine whether conventionally measured serum $\mathrm{HCO}_{3}{ }^{-}$(from peripheral venous blood) and calculated $\mathrm{HCO}_{3}{ }^{-}$values (from $\mathrm{ABG}$ analyzers) can be used interchangeably.

\section{Materials and Methods}

This study was conducted in the intensive care unit of a tertiary care teaching hospital of central Bangladesh from July to December 2011. A total of 51 patients, deemed by their treating doctor to require blood gas analysis either during initial evaluations or as part of their clinical care in ICU, were included in this study. After having the study explained, a verbal consent was obtained from the patient or their relative. Samples for arterial and venous blood gas analysis were obtained either by a registered nurse or a doctor as close as possible in time. The peripheral venous samples collected at the time of intravenous line insertion or as per recommendation were also used for other relevant blood tests. Multiple samples from the same patient at different dates were also accepted.

Calculated $\mathrm{HCO}_{3}{ }^{-}$concentrations were obtained from both arterial and venous blood gas samples using a Roche OPTI CCA op39090 instrument which calculates the $\mathrm{HCO}^{-}$concentration from the arterial $\mathrm{pH}$ and $\mathrm{PCO}_{2}$. The $\mathrm{HCO}_{3}^{-}$ concentration was directly measured in the same venous serum or plasma by means of ionselective electrodes (ISE). The samples were analyzed as quickly as possible using the blood gas analyzer routinely practiced in the ICU. Data were analyzed using SPSS version 12 and MedCal for Windows. Pearson's correlation and Bias plot (Bland \& Altman) ${ }^{16}$ method was used to compare the three measurements.

\section{Results}

In this study 57 matched sample pairs were collected from 51 patients (29 males 22 females) with mean $( \pm S D)$ of age $54 \pm 14$ years. The presenting diagnosis of the patients were: acute respiratory distress (33\%), acute coronary syndrome $(27 \%)$, acute on chronic renal failure (19\%), post-operative sepsis (15\%) and other suspected metabolic derangements $(1 \%)$. The mean $( \pm S D)$ calculated $\mathrm{HCO}_{3}$ - from arterial and venous gas analysis were $26.07( \pm 3.8) \mathrm{mEq} / \mathrm{L}, 26.58$ $( \pm 3.9) \mathrm{mEq} / \mathrm{L}$ respectively and conventionally measured serum $\mathrm{HCO}_{3}$ - value was 27.57 $( \pm 4.04) \mathrm{mEq} / \mathrm{L}$. The values shared highly significant correlation $(\mathrm{p}<0.0001 ; \mathrm{r}$ : $\mathrm{ABG}$ vs $\mathrm{VBG}=0.998$, measured serum vs $\mathrm{ABG}=0.984$ and measured serum vs $\mathrm{VBG}=0.986$ ). Table $\mathrm{I}$ shows the mean deference along with their $95 \%$ limits of agreement in Bland \& Altman comparison of measurements. 
Comparison of Conventionally Measured Serum Bicarbonate

Table I: Bland \& Altman comparison of Bicarbonate values in different methods.

\begin{tabular}{lcc}
\hline $\begin{array}{l}\text { Bicarbonate } \\
\text { Measurements }\end{array}$ & $\begin{array}{c}\text { Mean Difference } \\
(\mathrm{SD})(\mathrm{mEq} / \mathrm{L})\end{array}$ & $\begin{array}{c}\text { Bland - Altman 95\% } \\
\text { limits of Agreement (mEq/L) }\end{array}$ \\
\hline $\begin{array}{l}\text { Calculated Arterial vs } \\
\text { Venous Blood Gas }\end{array}$ & $0.51(0.22)$ & -0.07 to -0.95 \\
$\begin{array}{l}\text { HCO3- } \\
\text { Measured Serum vs } \\
\text { Calculated Arterial Blood } \\
\text { Gas HCO3 }\end{array}$ & $1.5(0.69)$ & --0.13 to -2.89 \\
$\begin{array}{l}\text { Measured Serum vs } \\
\text { Calculated Venous Blood } \\
\text { Gas HCO3 }\end{array}$ & $-0.99(0.65)$ & 0.29 to -2.27 \\
\end{tabular}

The bias plots (figs 1, 2 and 3), demonstrates acceptable agreement for all values of bicarbonate $(\mathrm{mEq} / \mathrm{l})$ with relative poor agreement for Measured Serum vs Calculated Arterial Blood Gas $\mathrm{HCO}_{3}-$ (fig 2).

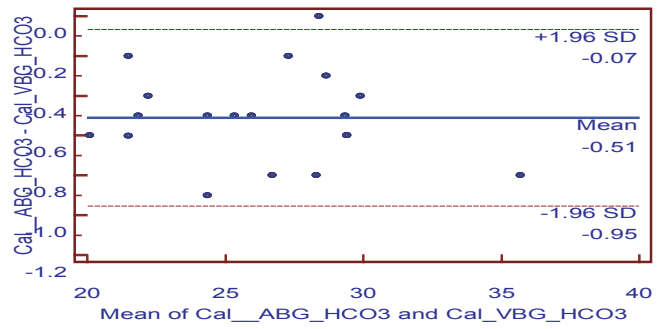

Figure 1: Bias plot comparing calculated arterial and venous blood gas HCO3- (Cal ABG: calculated arterial blood gas $\mathrm{HCO}_{3}-$, Cal VBG: calculated venous blood gas $\left.\mathrm{HCO}_{3}-\right)$

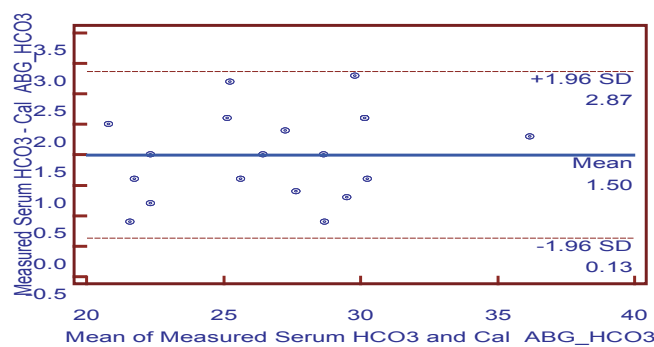

Figure 2: Bias plot comparing Measured Serum vs Calculated Arterial Blood Gas HCO3- (Cal ABG: calculated arterial blood gas $\mathrm{HCO}_{-}$)

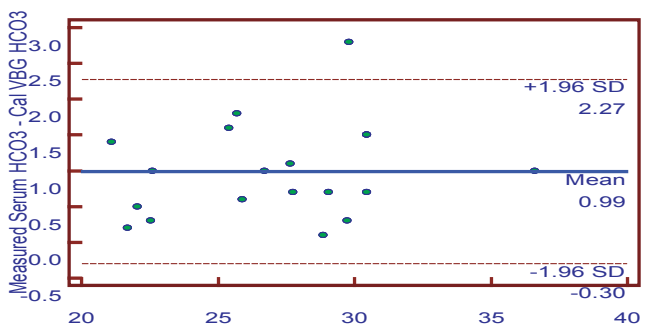

Mean of Measured Serum $\mathrm{HCO} 3$ and $\mathrm{Cal}$ VBG $\mathrm{HCO} 3$

Figure 3: Bias plot comparing Measured Serum vs Calculated Venous Blood Gas HCO3- (Cal VBG: Calculated Venous blood gas $\mathrm{HCO} 3-)$

\section{Discussion}

An important part of the assessment of the clinical status and progress of critically ill patients is timely assessment of acid-base status which is invariably practiced in arterial blood when it comes to blood gas analyzer. However, it may not always be practical to obtain arterial samples particularly in the early stages of resuscitation. Besides, such sophisticated device demands careful handling and adequate maintenance raising the cost of analysis. Plenty of reported evidence is available on agreement in ABG and VBG values but it does not reduce the cost load over a patient. So, this study was intended to focus on the unseen burdens over patient as well as the health care institutes and to look for a relatively easy, price-worthy and more specific way of measurement.

The agreement or discrepancy between measured and calculated bicarbonate and whether both can be used interchangeably has long been discussed since the $80^{\prime} \mathrm{s}^{11,12,17,18}$ without any concrete conclusion. With the advancement in the methodology, this issue seemed to have resurfaced with a couple of articles published since $2008^{8-10}$.

The correlation coefficient between the measured and calculated bicarbonate revealed a good correlation $(\mathrm{r}=0.977, \mathrm{p}<0.001)$. However the use of correlation coefficient alone to assess the agreement between two methods may not be appropriate as correlation depends on the range of values in the sample, a wide range of values like ours will yield a high correlation coefficient. Therefore, values which seem to be in poor agreement can produce high correlations provided the range is wide enough. Now, using Bland-Altman analysis, this study exhibited excellent agreement in the bicarbonate values. According the Bland-Altman analysis highest degree of agreement was found between VBG for $A B G$ bicarbonates ${ }^{3-8}$ followed by measured serum versus VBG and measured serum versus ABG bicarbonate ${ }^{9-12}$ estimates respectively unlike a few ${ }^{13-15}$. However, such comparisons of measured and calculated $\mathrm{HCO}_{3}{ }^{-}$values can be used to detect errors in the collection or analysis of blood samples. 
In a resource constrained third world country like ours, health professionals are often expected to manage within the limited facilities available especially in peripheral hospitals. Hence, conventional methods for estimation of serum HCO3- in critically ill ICU patients can be a convenient substitute for ABG. However, more accurate assessments will require $\mathrm{ABG}$ for additional parameters. Here, venous blood can be introduced to improve patients-doctors' compliance. Large scale studies with the same may add to it in future.

\section{References}

1. Scott MG, Klutts JS. Electrolytes and blood gases. In: Burtis CA, Ashwood ER, Bruns DE, editors. Tietz Textbook of Clinical Chemistry and Molecular Diagnostics. 4th ed. Missouri: Saunders; 2006:9831018.

2. Barker W J. Arterial puncture and cannulation. In: Roberts JR, Hedges JR, eds. Clinical procedures in emergency medicine, 3rd ed. Philadelphia: WB Saunders, 1998. 308-322.322.

3. Malatesha G, Singh NK, Bharija A, Rehani B, Goel A. Comparison of arterial and venous $\mathrm{pH}$, bicarbonate, $\mathrm{PCO}_{2}$ and $\mathrm{PO}_{2}$ in initial emergency department assessment. Emerg Med J. 2007 Aug; 24(8): 569-71.

4. Kelly AM, McAlpine R, Kyle E. Agreement between bicarbonate measured on arterial and venous blood gases. Emerg Med Australas 2004; 16(5-6): 407-9.

5. McCanny P, Bennett K, Staunton P, McMahon G. Venous vs arterial blood gases in the assessment of patients presenting with an exacerbation of chronic obstructive pulmonary disease. Am J Emerg Med 2012; 30(6): 896-900.

6. Razi E, Moosavi GA. Comparison of arterial and venous blood gases analysis in patients with exacerbation of chronic obstructive pulmonary disease. Saudi Med J 2007; 28(6):862-5.

7. Middleton P, Kelly AM, Brown J, Robertson M. Agreement between arterial and central venous values for $\mathrm{pH}$, bicarbonate, base excess, and lactate. Emerg Med J 2006; 23(8): 622-4.
W Nargis, BU Ahamed, Z Hossain, S Zabeen

8. Chu YC, Chen CZ, Lee CH, Chen CW, Chang HY, Hsiue TR. Prediction of arterial blood gas values from venous blood gas values in patients with acute respiratory failure receiving mechanical ventilation. J Formos Med Assoc 2003; 102(8):539-43.

9. Kumar V, Karon BS. Comparison of measured and calculated bicarbonate values. Clin Chem 2008; 54: 1586-7.

10. Chittamma A, Vanavanan S. Comparative study of calculated and measured total carbon dioxide. Clin Chem Lab Med 2008; 46:15-7.

11. Ungerer JPJ, Ungerer MJ, Vermask WJH. Discordance between measured and calculated total carbon dioxide. Clin Chem 1990; 36:2093-6.

12. Masters P, Blackburn MEC, Henderson MJ, Barrett JFR, Dear PRF. Determination of plasma bicarbonate of neonates in intensive care. Clin Chem 1988; 34: 1483-5.

13. Story DA, Poustie S. Agreement between two plasma bicarbonate assays in critically ill patients. Anaesth Intensive Care 2000; 28: 399-402.

14. Story DA, Poustie S, Bellomo R. Comparison of three methods to estimate plasma bicarbonate in critically ill patients: Henderson-Hasselbalch, enzymatic and strong-ion-gap. Anaesth Intensive Care 2001; 29: 585-90.

15. Lolekha PH, Boonlert W, Kost GJ, Vanavanan S, Lolekha S. Comparative study of values of calculated bicarbonate and measured total carbon dioxide content. Point of Care $=2003 ; 2: 135-43$.

16. Bland J M, Altman D G. Comparing methods of measurement: why plotting difference against standard method is misleading. Lancet 1995; 3461085-1087

17. Fezzotti A, Gambini AMM, Coppa G, De Sio G. Total carbon dioxide measured by the Vitros enzymatic method. Clin Chem Lab Med 1998; 36: 43-6.

18. O'Leary TD, Langton SR. Calculated bicarbonate or total carbon dioxide? Clin Chem 1989; 35: 1697-700. 